\title{
Experimental Analysis on Mechanical Performance of Recycled Concrete Made from Polypropylene Fiber and Artificial Sand
}

\author{
Huan Luo, Furong Ma*, Qian Yang \\ College of Civil Engineering, Guangxi Vocational Normal University, Nanning 530007, China
}

Corresponding Author Email: mfrong2004@163.com

https://doi.org/10.18280/acsm.440204

Received: 10 November 2019

Accepted: 17 January 2020

\author{
Keywords: \\ polypropylene fiber, artificial sand, recycled \\ concrete, compressive strength
}

\begin{abstract}
This paper aims to disclose the working performance and mechanical performance of recycled concrete made from polypropylene fiber and artificial sand (P-RCAS). Taking fiber content and concrete strength as variables, a total of 90 P-RCAS cubes and prisms were designed and prepared for axial loading tests. The working performance of the PRCAS was tested, the failure process and failure mode of the specimens were observed, and the compressive strengths of cubs and prisms were measured. Moreover, the authors probed deep into how fiber content affect the working performance and mechanical performance of the P-RCAS. The results show that adding polypropylene fiber into the artificial sand recycled concrete (RCAS) can produce concrete with good workability; the additional fibers help to enhance the compressive strength of RCAS specimens on all strength levels, but the enhancement was insignificantly for specimens on high strength levels. Finally, the test data were used to fit the calculation formulas for fiber content, water-cement ratio, and compressive strength, as well as the relationship between axial compressive strength and cube compressive strength. The research results provide reference for further research and engineering application of the RCAS.
\end{abstract}

\section{INTRODUCTION}

Concrete is the most widely used artificial material for civil construction. This composite material is prepared by mixing cementitious material, aggregate, and water in a proper ratio, and leaving the mixture to harden for a period. The aggregate in concrete mainly includes natural stones and river sands. Over the years, the stones and river sands in nature have gradually depleted, posing a great impact on the environment. Therefore, many scholars engaging in construction materials have attempted to develop recycled coarse aggregate concrete (RAC), that is, prepare recycled coarse aggregate from waste concrete and use them to make new concrete [1-3].

The physical-mechanical properties of concrete are affected by various factors, including the surface attachments of recycled aggregates, cracks induced by crushing, and the interface properties of aggregates. The relevant influence mechanism has deeply explored by scholars [4-5]. To improve the working performance of recycled concrete, some scholars [6-14] mixed a certain amount of polypropylene fiber into concrete, and studied the mechanical performance and crack resistance of polypropylene fiber recycled concrete. The results show that the proper addition of polypropylene fiber helps to enhance the compressive and flexural properties, reduce cracking, and improve durability of recycled concrete. However, the relevant studies only tackle the properties of the $\mathrm{RAC}$, failing to consider those of the recycled concrete made from artificial sand.

Sand, as a fine aggregate, is an important part of concrete. A huge amount of sand is consumed by concrete industry. To curb the excess exploitation of natural resources, many scholars have suggested replacing natural sand in concrete with artificial sand, creating the environmental-friendly green concrete. Thete et al. [15] explored the effect of using artificial sand instead of natural sand on the performance of ordinary concrete. Bhanuse et al. [16] examined the change of concrete strength after replacing natural sand with foundry waste sand. Bajad and Sakhare [17] investigated how concrete strength is affected by full replacement of natural sand with artificial sand prepared in quarries, revealing that the replacement enhances the strength and durability of concrete and mortar. Soundhirarajan ME and Valli [18] studied the change of concrete strength by replacing natural sand with artificial sand in quarry and believed that artificial sand in quarry was a good substitute.

The above studies mainly focus on the working performance and mechanical performance of the RAC, artificial sand concrete, and polypropylene fiber RAC. With the depletion of natural sand resource, many countries have banned the exploitation of this natural resource, which contradicts with the growing demand of sand for construction. It is an urgent task to replace natural sand with artificial sand, and substitute natural coarse aggregate with recycled coarse aggregate.

Therefore, this paper aims to clarify the working performance and mechanical performance of artificial sand RAC (RCAS), laying the basis for the development of green concrete, save natural resources, and protect the environment. To this end, $100 \%$ artificial sand and $100 \%$ recycled coarse aggregate were used to replace natural aggregate, producing a recycled concrete. Then, a certain amount of polypropylene fiber was added to the recycled concrete, creating a novel polypropylene fiber RCAS (P-RCAS). A total of 90 specimens were prepared for the P-RCAS, and subjected to tests on 
working performance and compressive strength. Through the tests, the authors investigated how the fiber content affects the working performance and mechanical performance of recycled concrete, and determined the optimal fiber content. In addition, the failure process and failure mode of the PRCAS were studied in details. The research findings provide a reference for the engineering application of the P-RCAS.

\section{METHODOLOGY}

\subsection{Materials and performance indices}

The following materials are used in our research:
(1) Cement: Conch P.O 42.5 ordinary Portland cement

(2) Coarse aggregate: the continuously graded recycled aggregate obtained by jaw crushing and sieving of waste concrete with a rebound strength of $46 \mathrm{MPa}$. The image and performance indices of the coarse aggregate are shown in Figure 1 and Table 1, respectively.

(3) Fine aggregate: artificial sand with 15\% stone powder. The image and performance indices of the fine aggregate are shown in Figure 2 and Table 2, respectively.

(4) Fiber: monofilament polypropylene fiber. The image and performance indices of the fiber are shown in Figure 3 and Table 3, respectively.

(5) Mixing water: tap water from municipal water supply system.

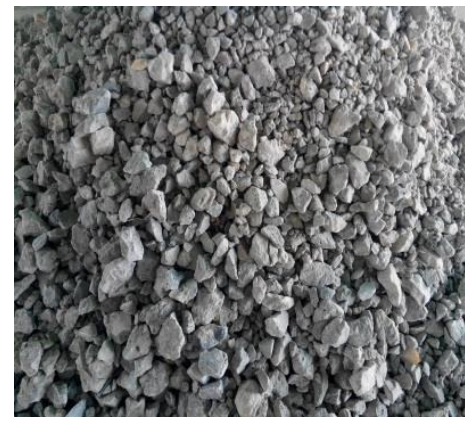

Figure 1. Recycled coarse aggregate

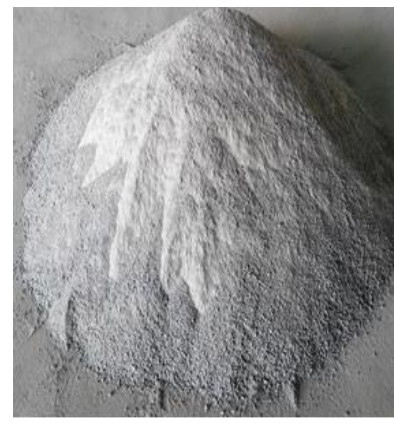

Figure 2. Artificial sand

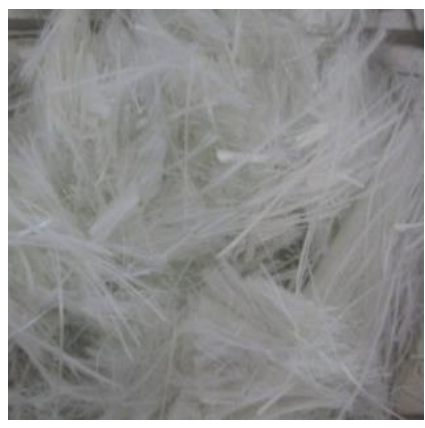

Figure 3. Polypropylene fiber

Table 1. Performance indices of coarse aggregate

\begin{tabular}{cccccc}
\hline Name & Gradation $/ \mathbf{m m}$ & $\begin{array}{c}\text { Water absorption } \\
\text { rate/\% }\end{array}$ & $\begin{array}{c}\text { Water } \\
\text { content } / \%\end{array}$ & Apparent density $/ \mathbf{k g} \cdot \mathbf{m}^{-3}$ & $\begin{array}{c}\text { Bulk } \\
\mathbf{d e n s i t y} / \mathbf{k g} \cdot \mathbf{m}^{-3}\end{array}$ \\
\hline Recycled coarse aggregate & $5-31.5$ & 3.5 & 0.2 & 2,615 & 1,200 \\
\hline
\end{tabular}

Table 2. Performance indices of fine aggregate

\begin{tabular}{cccccc}
\hline Name & Fineness modulus & Specification & Apparent density $/ \mathbf{k g} \cdot \mathbf{m}^{-3}$ & Bulk density $/ \mathbf{k g} \cdot \mathbf{m}^{-3}$ & Crush index \\
\hline Artificial sand & 2.86 & Medium sand & 2,702 & 1,581 & 21.3 \\
\hline
\end{tabular}

Table 3. Performance indices of polypropylene fiber

\begin{tabular}{ccccccc}
\hline Name & Density $/ \mathbf{g} \cdot \mathbf{c m}^{-3}$ & $\begin{array}{c}\text { Equivalent } \\
\text { diameter } / \mathbf{\mu m}\end{array}$ & $\begin{array}{c}\text { Elastic } \\
\text { modulus/MPa }\end{array}$ & $\begin{array}{c}\text { Tensile } \\
\text { strength/MPa }\end{array}$ & $\begin{array}{c}\text { Tensile } \\
\text { limit } / \%\end{array}$ & $\begin{array}{c}\text { Melting } \\
\text { point } /{ }^{\circ} \mathbf{C}\end{array}$ \\
\hline Polypropylene fiber & 0.91 & 26 & 3,815 & 560 & 27 & 170 \\
\hline
\end{tabular}

\subsection{Specimen preparation}

The concrete specimens of three ordinary strength levels were prepared according to the Specification for Mix Proportion Design of Ordinary Concrete (JGJ55-2011) and Technical Specification for Application of Fiber Reinforced Concrete (JGJ/T 221-2010). The concrete of each strength

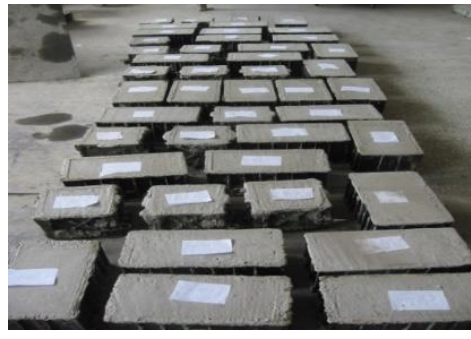

Figure 4. Some molding specimens level was mixed with polypropylene fiber. The mix ratios (mass ratios) are listed in Table 4.

A total of 45 cubes $(150 \mathrm{~mm} \times 150 \mathrm{~mm} \times 150 \mathrm{~mm})$ and 45 prisms $(150 \mathrm{~mm} \times 150 \mathrm{~mm} \times 300 \mathrm{~mm})$ were prepared. Some molding specimens are displayed in Figure 4, and some demolded specimens are presented in Figure 5.

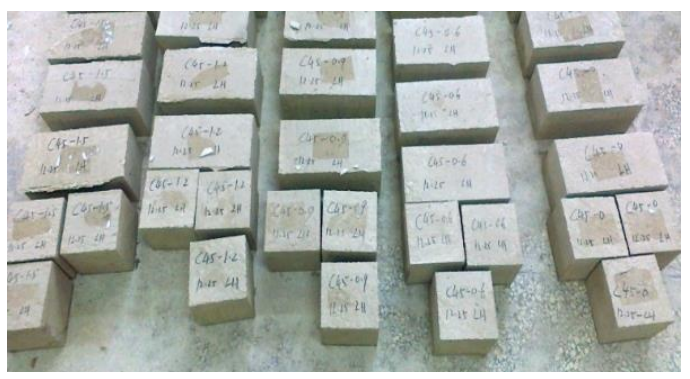

Figure 5. Some demolded and numbered specimens 
Table 4. Mix ratios of P-RCAS specimens

\begin{tabular}{|c|c|c|c|c|c|c|}
\hline No. & $\begin{array}{c}\text { Water- } \\
\text { cement ratio }\end{array}$ & $\begin{array}{c}\text { Fiber } \\
\text { content } / \mathbf{k g} \cdot \mathbf{m}^{-3}\end{array}$ & Water $/ \mathbf{k g} \cdot \mathbf{m}^{-3}$ & Cement $/ \mathrm{kg} \cdot \mathrm{m}^{-3}$ & $\begin{array}{c}\text { Artificial } \\
\text { sand } / \mathbf{k g} \cdot \mathbf{m}^{-3}\end{array}$ & $\begin{array}{l}\text { Recycled coarse } \\
\text { aggregate } / \mathbf{k g}^{-3} \mathbf{m}^{-3}\end{array}$ \\
\hline RCAS2500 & \multirow{5}{*}{0.6} & 0 & 185 & 308 & 793 & 1107 \\
\hline P-RCAS2506 & & 0.6 & 185 & 308 & 793 & 1107 \\
\hline P-RCAS2509 & & 0.9 & 185 & 308 & 793 & 1107 \\
\hline P-RCAS2512 & & 1.2 & 185 & 308 & 793 & 1107 \\
\hline P-RCAS2515 & & 1.5 & 185 & 308 & 793 & 1107 \\
\hline RCAS3500 & \multirow{5}{*}{0.49} & 0 & 185 & 378 & 702 & 1125 \\
\hline P-RCAS3506 & & 0.6 & 185 & 378 & 702 & 1125 \\
\hline P-RCAS3509 & & 0.9 & 185 & 378 & 702 & 1125 \\
\hline P-RCAS3512 & & 1.2 & 185 & 378 & 702 & 1125 \\
\hline P-RCAS3515 & & 1.5 & 185 & 378 & 702 & 1125 \\
\hline RCAS4500 & \multirow{5}{*}{0.34} & 0 & 185 & 545 & 645 & 1015 \\
\hline P-RCAS4506 & & 0.6 & 185 & 545 & 645 & 1015 \\
\hline P-RCAS4509 & & 0.9 & 185 & 545 & 645 & 1015 \\
\hline P-RCAS4512 & & 1.2 & 185 & 545 & 645 & 1015 \\
\hline P-RCAS4515 & & 1.5 & 185 & 545 & 645 & 1015 \\
\hline
\end{tabular}

Note: P is polypropylene fiber; RCAS is artificial sand recycled concrete; the first two figures after RCAS are the design strength of the concrete; the last two figures after RCAS are the fiber content of the concrete. For example, P-RCAS2515 means the design strength of the concrete is C25 and the fiber content is $1.5 \mathrm{~kg} / \mathrm{m}^{3}$ in the corresponding P-RCAS specimen.

Table 5. Test results on cube compressive strength and axial compressive strength of P-RCAS specimens

\begin{tabular}{|c|c|c|c|c|c|}
\hline No. & Water-cement ratio & Slump/mm & Cube compressive strength $f_{\text {cu }} / \mathrm{MPa}$ & Axial compressive strength $f_{\mathrm{c}} / \mathrm{MPa}$ & $f_{\mathrm{c}} / f_{\mathrm{cu}}$ \\
\hline RCAS2500 & & 65 & 30.8 & 26.8 & 0.87 \\
\hline P-RCAS2506 & & 58 & 33.9 & 30.8 & 0.91 \\
\hline P-RCAS2509 & 0.6 & 49 & 33.5 & 29.5 & 0.88 \\
\hline P-RCAS2512 & & 44 & 33.4 & 28.1 & 0.84 \\
\hline P-RCAS2515 & & 44 & 34.2 & 28.7 & 0.84 \\
\hline RCAS3500 & & 51 & 42.1 & 35.8 & 0.85 \\
\hline P-RCAS3506 & & 47 & 44 & 39.6 & 0.9 \\
\hline P-RCAS3509 & 0.49 & 42 & 42.3 & 36.8 & 0.87 \\
\hline P-RCAS3512 & & 40 & 44.6 & 37.9 & 0.85 \\
\hline P-RCAS 3515 & & 37 & 44.4 & 39.5 & 0.89 \\
\hline RCAS4500 & & 37 & 53.1 & 46.7 & 0.88 \\
\hline P-RCAS4506 & & 35 & 54 & 48.1 & 0.89 \\
\hline P-RCAS 4509 & 0.34 & 30 & 52.5 & 47.3 & 0.9 \\
\hline P-RCAS 4512 & & 26 & 53.2 & 45.2 & 0.85 \\
\hline P-RCAS 4515 & & 26 & 53.5 & 45.5 & 0.85 \\
\hline
\end{tabular}

To ensure the even distribution of fiber, dry mixing method was adopted. The feeding sequence and mixing time are as follows: recycled coarse aggregate, artificial sand, and polypropylene fiber were placed into a forced mixer and mixed for $60 \mathrm{~s}$; cement was added, and the mixture was stirred for $120 \mathrm{~s}$; water was added, and the mixture was stirred for 120s. After that, the specimens were cured indoor for $24 \mathrm{~h}$, numbered, and then demolded. Finally, the specimens were relocated to the lab for a $28 \mathrm{~d}$-long standard curing.

\subsection{Test methods and results}

According to the Standard for Test Method of Mechanical Properties on Ordinary Concrete (GB/T50081-2002), the specimens were subjected to multiple tests on cube compressive strength and axial compressive strength. After removing the outliers, the mean values were taken as the test results (Table 5).

\section{RESULTS ANALYSIS}

\subsection{Influence of fiber content on working performance}

Figure 6 shows the relationship between fiber content and slump of specimens with three different strength levels. It can be seen that the maximum slump appeared at the fiber content of zero; with the growth in fiber content, the slump exhibited a gradual decline. As the fiber content rose from $0 \mathrm{~kg} / \mathrm{m}^{3}$ to 1.5 $\mathrm{kg} / \mathrm{m}^{3}$, the slumps of $\mathrm{C} 25, \mathrm{C} 35$, and $\mathrm{C} 45$ specimens decreased by $21 \mathrm{~mm}(32 \%), 14 \mathrm{~mm}(27 \%)$, and $11 \mathrm{~mm}(30 \%)$, respectively.

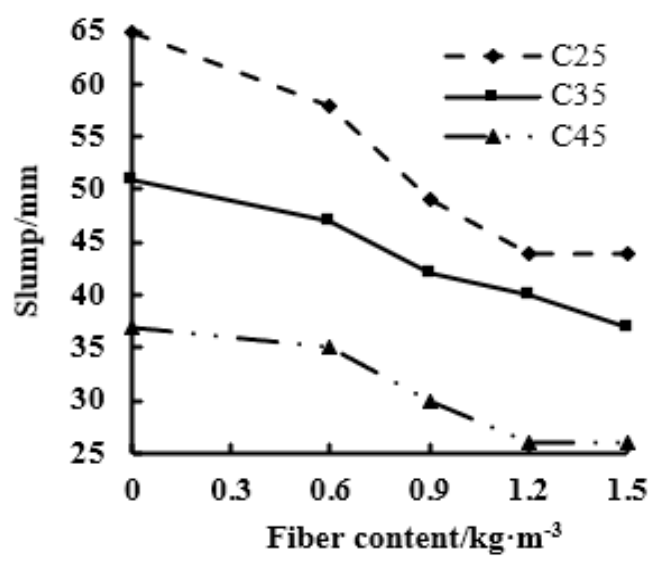

Figure 6. The relationship between fiber content and slump

The addition of fibers makes the mixture more viscous and less fluid. But the workability of the mixture meets the requirements. By dry mixing, the polypropylene fibers are 
evenly distributed in the concrete, and closely connected to cement mortar. In this way, both surface bleeding and aggregate segregation of the cement are suppressed, reducing the number of voids and the moving space of aggregates. The measured slump of each specimen falls in the specified range of plastic concrete, indicating that the P-RCAS meets the requirement on working performance.

\subsection{Strength of P-RCAS}

\subsubsection{Influence of fiber content on compressive strength}

Figure 7 presents the relationship between fiber content and compressive strength. It can be seen that polypropylene fiber had different impacts on the compressive strength of the RCAS, and the latter varied with fiber contents. For C25, C35, and $\mathrm{C} 45$ specimens, the maximum compressive strength was $11.0 \%, 5.7 \%$, and $1.7 \%$ higher than that of the RCAS without any polypropylene fiber, respectively. Hence, polypropylene fiber has a relatively large impact on low-strength RCAS. Moreover, when the fiber content was $0.6 \mathrm{~kg} / \mathrm{m}^{3}$, the compressive strength of $\mathrm{C} 25, \mathrm{C} 35$, and $\mathrm{C} 45$ specimens was $10.1 \%, 4.5 \%$, and $1.7 \%$ higher than that of the RCAS without any polypropylene fiber, respectively. This means the fiber content of $0.6 \mathrm{~kg} / \mathrm{m}^{3}$ could effectively enhance the strength of the RCAS on different strength levels.

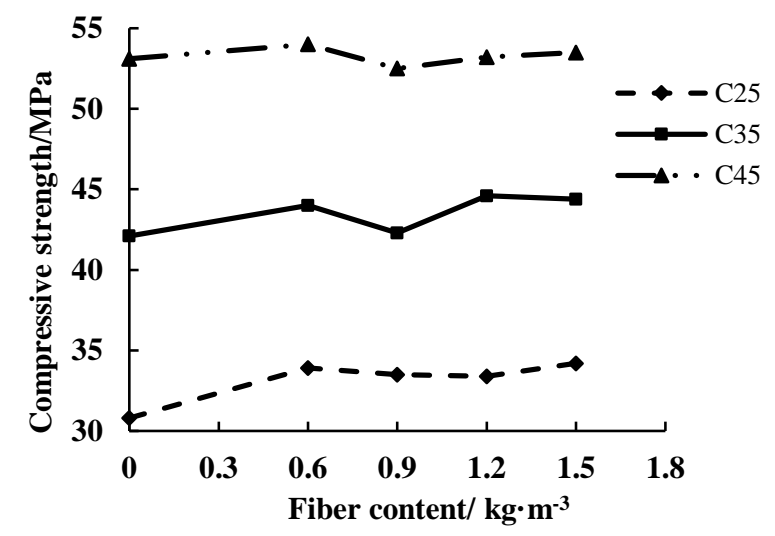

Figure 7. The relationship between fiber content and compressive strength

\subsubsection{Prediction of P-RCAS strength}

The water-cement ratio and fiber content have significant impact on P-RCAS strength. The results of compressive tests on P-RCAS indicate that the concrete strength is closely correlated with the water-cement ratio and fiber content.

Considering the impacts of water-cement ratio and fiber content, a binary regression model can be established for the strength of the P-RCAS:

$$
f_{c u}=a-b \rho_{w c}+c \omega_{p p f}
$$

where, $f_{c u}$ is the compressive strength of P-RCAS cubes; $\rho_{w c}$ is water-cement ratio; $\omega_{p p f}$ is fiber content.

The coefficients $a, b$, and c can be obtained by the least squares (LS) method from the measured data:

$$
f_{c u}=78.84-76.6 \rho_{w c}+1.16 \omega_{p p f}
$$

The R-Squared (the square of the Person Correlation Coefficient) $R^{2}=0.98$, indicating that the above equation has a high goodness-of-fit. Thus, the cube compressive strength is strongly linearly correlated with water-cement ratio and fiber content. The theoretical result only deviated from the measured data by $2 \%$ at the maximum.

3.2.3 Relationship between cube compressive strength and axial compressive strength

According to the measured data in Table 5, the ratio of axial compressive strength to cube compressive strength of the PRCAS fell between 0.84 and 0.91 , averaging at 0.87 . The mean ratio is slightly higher than that of ordinary concrete. This is because the additional fibers enhance the specimens' resistance to lateral deformation, and slows down the crack development and penetration. Therefore, both compressive strengths are increased by the fibers. The axial compressive strength grows faster than the cube compressive strength.

There is a certain correlation between the two compressive strengths. According to the Code for Design of Concrete Structures (GB50010 - 2010), the axial compressive strength should not be too high for the reason of safety and the brittleness of coarse aggregate. Hence, the mean values of the two compressive strengths were modified by the coefficients in the Code, and used to formulate the relationship between the two compressive strengths of the P-RCAS:

$$
f_{c}=0.88 \times 0.87 f_{c u}
$$

Eq. (3) shows that the axial compressive strength is 0.76 times the cube compressive strength. Thus, equation (3) can be rewritten as:

$$
f_{c}=0.76 f_{c u}
$$

where, $f_{c}$ and $f_{c u}$ are the axial compressive strength and cube compressive strength of the P-RCAS, respectively.

\subsection{Failure process and failure mode}

In the previous tests, both P-RCAS and RCAS specimens suffered from brittle failure. The failure mode was analyzed with $\mathrm{C} 35$ concrete specimens as examples. Figure 8 compares the pre- and post-failure images of RCAS3500 (without fibers) and P-RCAS3515 (with fibers).

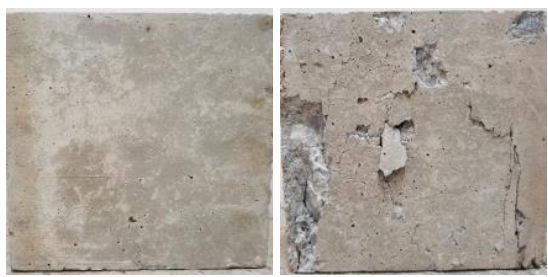

(a) RCAS3500

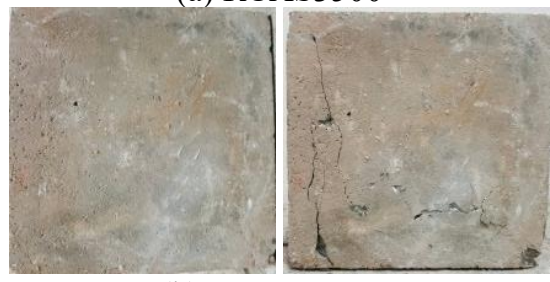

(b) P-RCAS3515

Figure 8. Failure forms of concrete specimens

For the RCAS specimen, visible micro cracks appeared on the surface, when the load approximated the maximum load. Due to the hoop effect, the micro cracks expanded and 
penetrated the specimen, once the load reached the maximum level. In some places, the concrete bulged and peeled off from the matrix, revealing the severity of brittle failure.

For the P-RCAS specimen, the failure process slightly differed from that of the RCAS, owing to the addition fibers. The fibers impeded cracks in the matrix, absorbed the cracking energy, and withstood part of the stress. Therefore, it took a longer time for the cracks to emerge, expand and penetrate the specimen. Finally, the specimen suffered from brittle failure with certain plastic deformation. The concrete did not bulge or peel off as severely as that of the RCAS specimen. Overall, the P-RCAS specimen was more complete than the RCAS specimen, showing better plasticity and ductility.

The good compressive strength of the P-RCAS specimen comes from the following: The crack development inside the concrete has a great influence on the deformation and failure of concrete. During the hardening process, the concrete will encounter shrinkage stresses from drying, temperature, and carbonization. When these shrinkage forces surpass the tensile strength of the cement matrix, many primary cracks and pores of different sizes will appear inside the concrete. These initial defects are the main influencing factors of concrete strength. The polypropylene fibers, which are randomly distributed, can be closely combined with the cement matrix. The good adhesion of the fibers prevents cracks from emerging due to the early expansion and contraction induced by hydration heat, and mitigates the concentration of internal stress, thereby enhancing the compressive strength of the P-RCAS specimen. Meanwhile, the strong tensile strength of the fibers delays the cracking of the concrete, which also elevates the compressive strength of the P-RCAS specimen.

From the failure process and the impacts of fiber content on compressive strength, it can be seen that adding polypropylene fiber to the concrete matrix is an effective way to improve the compressive strength of concrete. The additional fibers improve the concrete performance, especially the compressive strength of the RCAS.

\section{CONCLUSIONS}

(1) With the increase of fiber content, specimens on different strength levels only suffered limited slump loss; the mixture had good cohesiveness, water retention and fluidity. It is possible to prepare plastic concrete with good workability by adding polypropylene fiber into the RCAS.

(2) Thanks to the bridging effect of the fibers inside the matrix, the P-RCAS specimens exhibited brittle failure with certain plastic deformation on the macroscale. After failure, the P-RCAS specimen was more complete than the RCAS specimen.

(3) The additional fibers enhance the strength of the RCAS, especially the specimen with a low strength level. The addition of polypropylene fiber increased the compressive strength of this specimen by 1.11 times. The optimal fiber content varies with the strength levels of concrete. However, the concretes at all strength levels saw effectively growth in compressive strength, at the low fiber content of $0.6 \mathrm{~kg} / \mathrm{m}^{3}$. Therefore, this fiber content was recommended as the proper value.

(4) The authors established the mathematical expression between water-cement ratio, fiber content, and compressive strength. For the P-RCAS, the ratio of axial compressive strength to cube compressive strength was recommended to be 0.76 .

\section{ACKNOWLEDGMENT}

This paper was supported by Project to improve the basic scientific research ability of young and middle-aged teachers in Guangxi Universities (2020KY25014); Project to improve the basic scientific research ability of young and middle-aged teachers in Guangxi Universities (2020KY25015).

\section{REFERENCES}

[1] Etxeberria, M., Vázquez, E., Marí, A., Barra, M. (2007). Influence of amount of recycled coarse aggregates and production process on properties of recycled aggregate concrete. Cement and Concrete Research, 37(5): 735-742. https://doi.org/10.1016/j.cemconres.2007.02.002

[2] Huda, S.B., Alam, M.S. (2014). Mechanical behavior of three generations of $100 \%$ repeated recycled coarse aggregate concrete. Construction and Building Materials, 65: 574-582. https://doi.org/10.1016/j.conbuildmat.2014.05.010

[3] Nili, M., Sasanipour, H., Aslani, F. (2019). The effect of fine and coarse recycled aggregates on fresh and mechanical properties of self-compacting concrete. Materials, 12(7):

https://doi.org/10.3390/ma12071120

[4] Kim, Y., Hanif, A., Usman, M., Park, W. (2019). Influence of bonded mortar of recycled concrete aggregates on interfacial characteristics-porosity assessment based on pore segmentation from backscattered electron image analysis. Construction and Building Materials, 212: 149-163. https://doi.org/10.1016/j.conbuildmat.2019.03.265

[5] Alexandridou, C., Angelopoulos, G.N., Coutelieris, F.A. (2018). Mechanical and durability performance of concrete produced with recycled aggregates from Greek construction and demolition waste plants. Journal of Cleaner Production, 176: 745-757. https://doi.org/10.1016/j.jclepro.2017.12.081

[6] Hossain, F.Z., Shahjalal, M., Islam, K., Tiznobaik, M., Alam, M.S. (2019). Mechanical properties of recycled aggregate concrete containing crumb rubber and polypropylene fiber. Construction and Building Materials, 225: 983-996. https://doi.org/10.1016/j.conbuildmat.2019.07.245

[7] Vytlacilova, V. (2012). Mechanical-physical characteristics affecting the durability of fibre reinforced concrete with recycled aggregate. World Academy of Science, Engineering and Technology, 6(4): 1152-1158.

[8] Hussien, A.A., El-hameed, G.D.A., Hadhood, H.M., Elattar, A.G. (2015). Properties of normal and high strength fiber reinforced concrete using recycled aggregate and different fibers. World Applied Sciences Journal, 33(11): 1676-1685. https://doi.org/10.5829/idosi.wasj.2015.33.11.15620

[9] Akça, K.R., Çakır, Ö., İpek, M. (2015). Properties of polypropylene fiber reinforced concrete using recycled aggregates. Construction and Building Materials, 98: 620-630. https://doi.org/10.1016/j.conbuildmat.2015.08.133

[10] Hong, S.U., Lee, Y.T., Kim, S.H., Baek, S.K., Cho, Y.S. (2012). Strength properties of recycled aggregate concrete mixed with polypropylene fiber. In Applied Mechanics and Materials, 147: 28-31. 
https://doi.org/10.4028/www.scientific.net/AMM.147.2 8

[11] Kumar, D.N., Rao, T.V., Madhu, T., Saroja, P.L.N., Prasad, D.S.V. (2014). An experimental study of recycled concrete with polypropylene fiber. International Journal of Innovative Research in Advanced Engineering, 2349-2163.

[12] Madhavi, T.C., Mallick, A., Sohail, M.B., Nath, S., Jain, M. (2015). Effect of copper slag on strength of polypropylene fiber reinforced concrete. Internal J. Eng. Technol, 7(4): 1309-1322.

[13] Zia, A., Ali, M. (2018). Effectiveness of polypropylene fiber reinforced concrete in enhancement of long-term durability of hydraulic structures. In Materials Science Forum, 923:

125-129. https://doi.org/10.4028/www.scientific.net/MSF.923.12 5

[14] Selvamony, C., Ravikumar, M.S., Kannan, S.U., Gnanappa, S.B. (2010). Investigations on self-compacted self-curing concrete using limestone powder and clinkers. ARPN Journal of Engineering and Applied Sciences, 5(3): 37585-37594.

[15] Thete, H., Adole, R., Bankar, O., Tayade, B., Bodke, S.S. (2018). Replacement of natural sand by artificial sand \& its effect on cost and compressive strength of concrete. International Journal of Scientific Research in Science, Engineering and Technology, 4(4): 538-542.

[16] Bhanuse, M.M., Patil, S.S., Katti, M.R., Jadhav, R.V. (2018). To study the strength of concrete due to partial replacement of river sand by waste foundry sand. Indian Journal of Environmental Protection, 38(12): 1051-1055.

[17] Bajad, M.N., Sakhare, S. (2018). Influence of artificial sand on the properties of concrete and mortar. Technology, 9(1): 447-454.

[18] Soundhirarajan ME, K., Valli, M.N. (2018). Use of quarry dust to replace sand concrete: An experimental study. National Journal of Multidisciplinary Research and Development, 3(1): 1163-1167. 